\title{
Sublethal exposure to clothianidin during the larval stage causes long-term impairment of hygienic and foraging be- haviours of honey bees
}

\author{
Nuria Morfin ${ }^{1}$, Paul H. Goodwin ${ }^{1}$, Adriana CoRrea-BenITEZ ${ }^{2}$, \\ Ernesto GuzMan-NovoA ${ }^{1}$

\begin{abstract}
${ }^{1}$ School of Environmental Sciences, University of Guelph, 50 Stone Road East, Guelph, ON N1G 2W1, Canada
\end{abstract} \\ ${ }^{2}$ Departamento de Abejas, Conejos y Organismos Acuáticos, FMVZ, UNAM, Mexico City, Mexico
}

Received 28 February 2019 - Revised 20 May 2019 - Accepted 24 June 2019

\begin{abstract}
Most studies on the effects of neonicotinoid insecticides on neural processes of honey bees are based on behaviours performed by adult bees exposed as adults. It is unclear how the developing brains of honey bee larvae are affected by sublethal doses of neonicotinoid insecticides when measuring neural processes through behavioural performance in adult bees. In this study, larvae were exposed to three sublethal doses of clothianidin and evaluated 25-36 days later for hygienic and foraging behaviours as adult bees. The medium and highest sublethal doses of clothianidin significantly reduced hygienic and foraging activity. The greatest effects were on the proportion of adult bees foraging and carrying pollen. These results show that exposure of larvae to clothianidin results in negative effects extending into the adulthood of bees, possibly compromising the colony's fitness by impairing pathogen control mechanisms and by reducing pollen collection.
\end{abstract}

\section{honey bee larvae / hygienic behavior / foraging behavior / neonicotinoids / neural processes}

\section{INTRODUCTION}

Honey bees (Apis mellifera L.) are social organisms that live in colonies where cooperation and complex interactions among members occur (Page Jr 2012). Some behaviours performed by individual bees are indispensable for colony survival and reproduction (e.g., foraging and guarding behaviours) (Winston 1991) and others provide resistance to the colony against parasites and diseases (e.g., hygienic and grooming behaviours) (Spivak 1996; Spivak and Reuter 2001). Neural processes are needed to perform these behaviours. Neural processes allow animals to

Corresponding author: N. Morfin, nmorfinr@uoguelph.ca

Handling editor: Monique Gauthier perceive stimuli from the environment and react to them (Webb 2012). For hygienic behaviour, middle-aged workers identify diseased or dead larvae or pupae using olfactory cues, and then through the action of neuromodulators, like octopamine, they uncap cells and remove the affected larvae or pupae from the colony (Arathi et al. 2000; Spivak et al. 2003). Similarly, neural processes play an important role in foraging behaviour by enabling bees to locate food sources through odour cues and then determining direction and distance to the food source, which is conveyed in the waggle dance to other bees (Esch 2012).

Neural processes can be affected when honey bees are exposed to chemical stressors, such as neurotoxic insecticides that are detrimental to the central nervous system (Costa et al. 2008). One of the most common class of neurotoxins used in 
agriculture are the neonicotinoid insecticides, which act by binding to nicotinic acetylcholine receptors (nAChRs) in the central nervous system overstimulating neurotransmission (Tomizawa and Casida 2008). In Canada and the USA, thiamethoxam and clothianidin are two of the most widely used neonicotinoids in field crops, particularly in corn and canola (Uneme 2010). Adult honey bees can be repeatedly exposed to sublethal concentrations of neonicotinoids by collecting contaminated nectar and/or pollen from treated plants and wild flowers growing near treated crops (Pisa et al. 2015), and larvae fed with these products could also be repeatedly exposed to these neurotoxins. There are no reports on the effects of sublethal exposure to neonicotinoid insecticides on foraging and hygienic behaviours in adult bees when the bees were treated individually during the larval stage, but instead, studies have examined the effect of chronic sublethal exposure on hygienic and foraging behaviours of all bees treated at a colony level (Dively et al. 2015; WuSmart and Spivak 2016; Tsvetkov et al. 2017). Few studies have assessed the effect of neonicotinoid exposure during the larval stage on traits associated with neural processes, such as associative learning in bees (Yang et al. 2012; Tan et al. 2015). Exposure to rapidly developing honey bee larvae may result in neurodevelopmental abnormalities as activation of neurotransmitter receptors during early development in animals controls a range of factors, such as neural replication, synapse and axon formation and localization of cell populations within the central nervous system (Slotkin 2004). Thus, the developing central nervous system is highly vulnerable, and a number of studies have demonstrated long-term, adverse affects caused by chemicals that alter acetylcholine systems on brain cells and eventually behaviour (Slotkin 2004). For example, prenatal exposure to nicotine, which acts as agonist of acetylcholine receptors like neonicotinoid insecticides, resulted in impaired synaptic activity in rats, even at 23 days after exposure (Zahalka et al. 1992). Also, rats exposed to nicotine during adolescence showed impairment in attention span and reduction on presynaptic terminal of prefrontal cortex glutamatergic synapses at 35 days after treatment (Counotte et al. 2011). For honey bees, neonicotinoid exposure during the larval developmental stage could have long-term detrimental effects on later neural processes, such as when adult bees perform foraging and hygienic behaviour. In this study, honey bee larvae were repeatedly exposed to sublethal doses of clothianidin, and the adults that developed from these larvae were assessed for hygienic and foraging behaviours to determine the long-term impact of the neurotoxin.

\section{METHODS}

\subsection{Source of honey bees}

The honey bees used in the experiments were collected from colonies of the Buckfast strain maintained at the University of Guelph's Honey Bee Research Centre in Ontario, Canada. The queens that provided the larvae used in this study were mated under controlled conditions in isolation at Thorah Island, Simcoe, ON, to guarantee the purity and uniformity of the Buckfast strain.

\subsection{Clothianidin working solutions}

To estimate the amount of clothianidin used in the experiments, the predicted concentration of clothianidin in maize pollen of plants from insecticide-treated seeds (0.0011 to $0.015 \mathrm{ng}$ clothianidin/mg of pollen; EFSA 2013) and total amount of pollen consumed by a single worker honey bee larva (125 to $145 \mathrm{mg}$ pollen/bee; Winston 1991) were considered. Thus, the minimum amount of clothianidin that a honey bee larva could potentially consume in the pollen during the larval stage was calculated: $(0.0011 \mathrm{ng}$ clothianidin $/ \mathrm{mg}$ pollen $)(120 \mathrm{mg}$ pollen $/ \mathrm{bee})=$ $0.13 \mathrm{ng}$ clothianidin/bee. The maximum amount of clothianidin that a honey bee larva could potentially consume in the pollen during the larval stage was calculated: $(0.015 \mathrm{ng}$ clothianidin $/ \mathrm{mg}$ pollen $)(150 \mathrm{mg}$ pollen/bee $)=2.20 \mathrm{ng}$ clothianidin/bee. Hence, the range of clothianidin consumption was estimated to be $0.13-2.20 \mathrm{ng}$ clothianidin/bee $(\bar{x}=1.16 \pm 0.73 \mathrm{ng})$, and the three doses used in this study were within that range at $0.13,0.67$ and $1.33 \mathrm{ng}$ clothianidin/bee. To prepare the working clothianidin solutions, $10 \mathrm{mg}$ clothianidin (Sigma Aldrich®, Oakville, 
ON, Canada) was diluted in $100 \mathrm{ml}$ of $\mathrm{ds} \mathrm{H}_{2} \mathrm{O}$. Subsequently, serial dilutions were made to obtain $1000 \mathrm{ng} / \mathrm{ml}, 500 \mathrm{ng} / \mathrm{ml}$, and $100 \mathrm{ng} / \mathrm{ml}$.

\subsection{Exposure of larvae to clothianidin}

To obtain larvae of the same age, each of four sister queens were placed on an empty comb inside modified hives that had two wire mesh walls (queen-excluder size) at their centre to house a frame of drawn, empty comb and a queen. The mesh allowed the passage of worker bees but kept the queen confined to lay eggs on the comb. When abundant eggs were observed on the comb, usually after 1 day, the queen was moved out of the confined area within the same colony to prevent her from laying more eggs of different age on the comb. At least 500 larvae that hatched from the eggs of the four combs were used for each of the four treatments.

Four-day-old larvae (4th instar larvae) were each treated for three consecutive days with $1.33 \mu \mathrm{l}$ of $\mathrm{ds} \mathrm{H}_{2} \mathrm{O}$ without clothianidin $(0 \mathrm{ng}$, control) or containing $0.13,0.67$ or $1.33 \mathrm{ng}$ of clothianidin. After each treatment, the frames with the treated larvae were returned to their respective colonies to continue development in normal conditions until adulthood, as per Hamiduzzaman et al. (2012). The colonies used in the experiment were not exposed to pesticides at any time and were uniform in terms of size and food storage. One day before adult bees hatched, the frames were retrieved from their hives and placed inside emerging wooden cages $(50.3 \times 7.3 \times 25.2 \mathrm{~cm})$ and incubated $\left(35^{\circ} \mathrm{C}, 60 \% \mathrm{RH}\right)$ until the bees emerged. This procedure was done for each of the three repetitions of hygienic and foraging experiments. The mortality of treated larvae was recorded, but it was negligible as there was no difference between treatments as it was less than $1 \%$ for all the treatments.

\subsection{Establishment of observation hives}

Three observation hives $(47 \times 4.1 \times 96 \mathrm{~cm})$ were established using combs from healthy, randomly selected colonies. Four frames with about 4000 worker bees and a queen were installed in each of the observation hives.
One side of the hive was covered with glass and the opposite side with plexiglass. The plexiglass side had a door $(10 \times 10 \mathrm{~cm})$ near the bottom of the hive that was later used to introduce a comb section containing recently sacrificed brood through freezing to study the hygienic response. The observation hives were installed inside a building with no windows and kept at room temperature $\left(20-30^{\circ} \mathrm{C}\right)$, covered with a cotton cloth at all times, except during observations. The hives were connected to the exterior of the building with wooden ramps to allow exit and entrance of bees. The ramp of each observation hive was covered with glass on the top, and below the glass, it was divided into two lanes by a barrier along its length to separate the outgoing and incoming bees, which facilitated the observation of marked bees as they left or entered the hive (Guzman-Novoa and Gary 1993).

\subsection{Observations of hygienic events}

For each treatment, 198 newly emerged bees (792 bees in total) were identified by gluing numbered plastic tags (Graze Bienenzuchtgeräte, Weinstadt, DE) onto their thoraces. Tags of different colours were used to identify bees of the different treatments, and each bee was identified with a specific number, allowing for individual identification. The colours used to identify the bees of each treatment were changed in each of the three repetitions to avoid bias from the observer, who did not know which colours corresponded to a treatment.

The tagged bees were introduced into the previously established observation hives. Censuses were conducted 1 day before the first of three hygienic behaviour observation days to determine the number of treated bees that remained alive in each hive. Censuses were done visually by recording the numbers and colours of live tagged bees inside the observation hives and were done at night (22:00 $\mathrm{h}$ EST), when there was no foraging activity to ensure that all the bees were inside the observation hives (Unger and Guzman-Novoa 2010).

To analyse hygienic behaviour, a $9 \times 9-\mathrm{cm} \mathrm{sec}-$ tion of comb containing freeze-killed brood was 
introduced into the observation hive through the $10 \times 10-\mathrm{cm}$ plexiglass door and fixed with toothpicks to a comb inside the hive. The comb had an open space of the same dimensions of the comb section (Unger and Guzman-Novoa 2010). Hygienic events performed by the tagged bees in the area of the freeze-killed brood were recorded on three consecutive days when the bees were 12 , 13 and 14 days old. Daily observations were done from 9:00 to 17:00 EST. Hygienic events consisted of bees uncapping cells and/or removing dead brood from them. The observer moved every $15 \mathrm{~min}$ from one side of the observation hive to the other to avoid bias. The colour and number of the bee tag was recorded when a hygienic event was observed. If a bee was still performing a hygienic event after a 15-min cycle (observer switching sides), two hygienic events were recorded. Also, if a bee suspended the event to perform another behaviour and then went back to performing a hygienic event, a new record was annotated (Unger and Guzman-Novoa 2010). The number of live bees in the hive $(80 \pm 3)$ from the most recent census together with the number of bees performing hygienic events during observations for each of the treatment groups were used to calculate the proportion of surviving bees performing hygienic events (PSBH), and this proportion was used for statistical analysis. Three repetitions of the experiment were performed.

\subsection{Observations of foraging behaviour}

Four-day-old larvae were obtained and treated as above, but for each treatment, 396 newly emerged bees ( 1584 bees in total) were identified with plastic tags of different colours as previously described and introduced into three observation hives. As before, censuses were conducted when the bees were 12, 17 and 22 days old.

To analyse foraging behaviour, the departure and return times of the tagged bees were recorded from 9:00 to 12:00 EST and from 13:00 to 16:00 EST for 12 consecutive days starting when the bees were 12 days old. Foraging activity was recorded as per
Guzman-Novoa and Gary (1993). Briefly, the departure and return times of tagged bees, as well as the presence of pollen, were recorded by observing the bees on the glasscovered ramps, which were connected to the observation hives as previously described. Round trips of less than 3 min were excluded from the analysis to avoid the inclusion of bees conducting orientation or defecation flights. Taking into consideration the number of bees alive from the censuses, the proportion of surviving bees foraging (PSBF), the proportion of foraging bees carrying pollen (PFBP) and the proportion of surviving bees carrying pollen (PSBP) were calculated. Additionally, the mean duration of round trips (DRT) was estimated. Three repetitions of the experiment were performed.

\subsection{Statistical analysis}

Survivorship, PSBH and DRT data were tested for normality using the Shapiro-Wilk test. Since they did not comply with the test, the data of surviving bees during observations and the PSBH were arcsine square-root transformed, whereas the DRT data were transformed to a base 10 logarithm before subjecting them to a one-way analysis of variance and Fisher's LSD tests, with $\alpha$ of 0.05 when significance was detected. The PSBF, PFBP and the PSBP data were analysed with contingency tables using $\chi^{2}$ tests of independence with $\alpha$ of 0.05 . Adjusted residuals were calculated for post hoc analysis. A correlation analysis was performed to determine the association between sublethal doses of clothianidin and PSBH, PSBF and PFBP using arcsine square-root transformed data. The statistical analyses were done using R, version 3.4.3@ (The R Core Team 2014).

\subsection{Data availability}

The dataset generated during and/or analysed during the current study are available from the corresponding author on reasonable request. 


\section{RESULTS}

\subsection{Hygienic behaviour}

Exposure to the sublethal doses of clothianidin during the larval stage did not significantly affect the number of treated bees that were alive during the 3 days of hygienic behaviour observations, which ranged from 60 to 113 per treatment $\left(F_{(3,32)}=2.30\right.$, $P=0.096)$. However, compared with the control ( $0 \mathrm{ng}$ ), the exposure of larvae to 0.67 and $1.33 \mathrm{ng} /$ day of clothianidin resulted in PSBH values that were 1.5 and 2.3 times lower, respectively, compared to the control, both of which were significantly different from it $\left(F_{(3,32)}=3.99, P=0.016\right.$; Figure 1). Therefore, the decrease in PSBH was associated with the medium and high sublethal doses of clothianidin, and there was a negative correlation between sublethal doses of clothianidin and PSBH $(r=-0.49, N=36, P=0.002)$, indicating a dose response over the range tested.

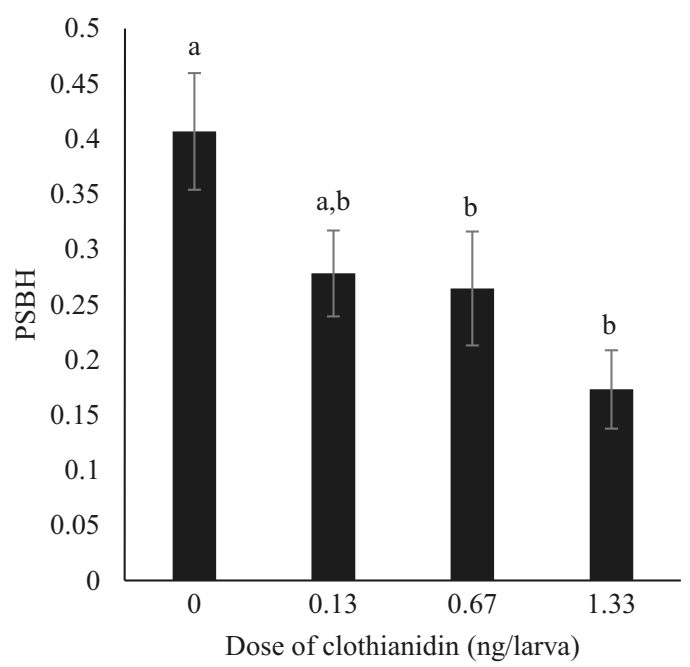

Figure 1. Mean proportion of bees performing hygienic events (PSBH) by surviving bees that were exposed to sublethal doses of clothianidin during their larval stage on days 12,13 and 14 post emergence. The summed data were arcsine square root transformed and subjected to a one-way ANOVA and Fisher LSD tests with an $\alpha$ of 0.05. Nontransformed data are presented.

\subsection{Foraging behaviour}

Exposure to the three sublethal doses of clothianidin during the larval stage did not significantly affect the number of treated bees that were alive during the 12 days of foraging observations, which ranged from 100 to 196 (x $152 \pm 4)\left(F_{(3,32)}=1.37, P=\right.$ $0.27)$. However, PSBF during the 12 days of observations was significantly reduced in bees treated with $0.67 \mathrm{ng} /$ day and $1.33 \mathrm{ng} /$ day of clothianidin $\left(\chi_{(3,29,457)}^{2}=94.47\right.$, $P<0.0001$; Figure 2), which was 1.34 and 1.16 times lower than the control, respectively. The lowest PSBF was with $0.67 \mathrm{ng} /$ day, which was also significantly lower than the PSBF for larvae treated with $1.33 \mathrm{ng}$ /day $\left(\chi_{(1,13,858)}^{2}=13.24, P<0.0001\right)$. There was no significant correlation between sublethal doses of clothianidin and PSBF $(r=-0.13$, $N=144, P=0.119$ ).

There was also a significant reduction in PFBP when larvae were treated with 0.67 and $1.33 \mathrm{ng} /$ day of clothianidin $\left(\chi_{(1,7373)}^{2}=44.95, P<0.0001\right.$;

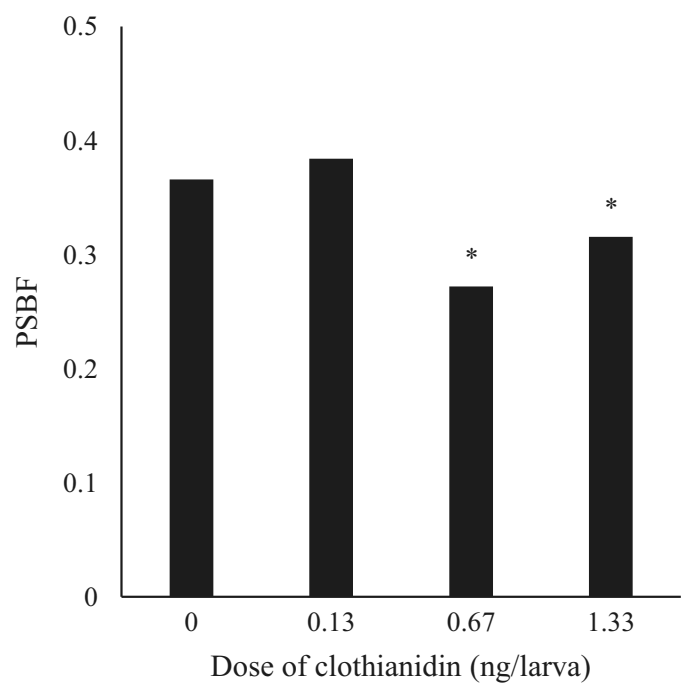

Figure 2. Proportion of surviving bees foraging (PSBF) that developed from larvae exposed to sublethal doses of clothianidin. Asterisks above a bar indicate a significant difference with the control based on $\chi^{2}$ analysis and adjusted residuals with an $\alpha$ of 0.05 . 


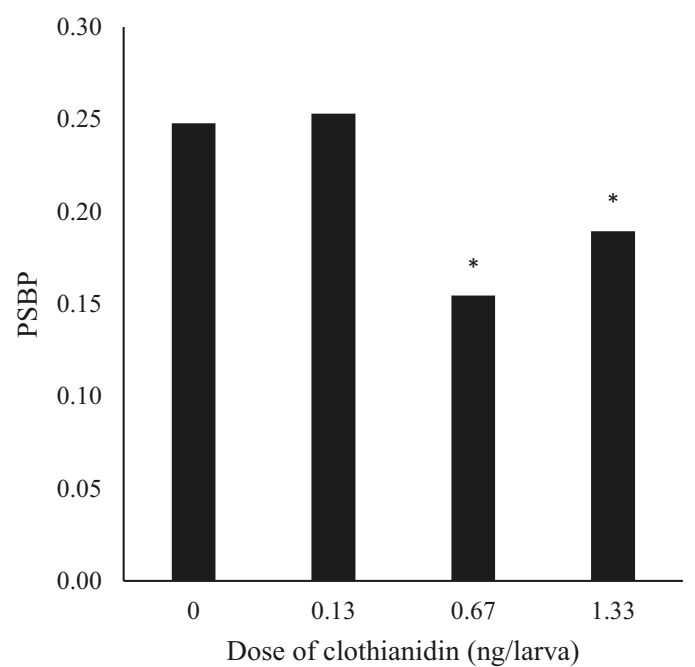

Figure 3. Proportion of foraging bees carrying pollen (PFBP) that developed from larvae exposed to sublethal doses of clothianidin. Asterisks above a bar indicate a significant difference with the control based on $\chi^{2}$ analysis and adjusted residuals with an $\alpha$ of 0.05 .

Figure 3). The PFBP from larvae that were treated with 0.67 and $1.33 \mathrm{ng} /$ day of clothianidin was 1.16 and 1.13 times lower than the control. However, there was no difference in the PFBP between bees

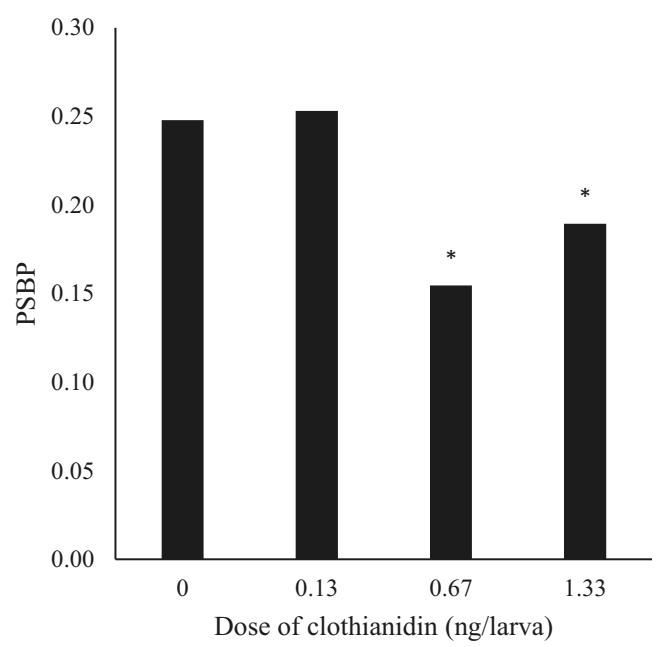

Figure 4. Proportion of surviving bees carrying pollen (PSBP) that developed from larvae exposed to sublethal doses of clothianidin. Asterisks above a bar indicate a significant difference with the control based on $\chi^{2}$ analysis and adjusted residuals with an $\alpha$ of 0.05 .



Figure 5. Mean duration of round trips (DRT) that developed from larvae exposed to sublethal doses of clothianidin. The summed data were transformed to a base 10 logarithm before subjecting them to a one-way ANOVA and Fisher's LSD tests, with $\alpha$ of 0.05 . Nontransformed data are presented.

treated with 0.67 and $1.33 \mathrm{ng} /$ day of clothianidin $\left(\chi_{(1,3115)}^{2}=0.80, P=0.37\right)$. There was no correlation between sublethal doses of clothianidin and PFBP $(r=-0.011, N=144, P=0.90)$.

Based on PSBF and PFBP, PSBP was determined and revealed that $0.25,0.25,0.15$ and 0.19 of the surviving bees were returning with pollen for the $0,0.13,0.67$ and $1.33 \mathrm{ng} /$ day clothianidin treatments, respectively. The effects of the 0.67 and $1.33 \mathrm{ng} /$ day significantly reduced PSBP $\left(\chi_{(1}^{2}\right.$, 22,045) $=224.07, P<0.0001$; Figure 4).

The summed data of the DRT of foraging bees from the 12 days of observation revealed no significant effect of larval sublethal exposure to clothianidin $\left(F_{(3,1906)}=0.50, P=0.68 ;\right.$ Figure 5).

\section{DISCUSSION}

Exposing larvae to the sublethal doses of clothianidin for 3 days did not affect adult bee survivorship when later tested for hygienic or foraging behaviour, which was 25-27 to 25-36 days after the final exposures, respectively. This is not unexpected as the sublethal doses used in this study were 
29, 5.6 and 2.8 times lower than the oral $\mathrm{LD}_{50}$ for clothianidin (EFSA 2013). Similarly, Doublet et al. (2015) found no increase in mortality of developing bees after feeding larvae for 5 days with the neonicotinoid insecticide thiacloprid at a dose $1.73 \times 10^{4}$ times lower than the oral $\mathrm{LD}_{50}(\mathrm{FAO}$ 2010). Also, no effects on survivorship were observed for 5-day-old adult bees after feeding them for 20 days with a sublethal dose of thiacloprid at a dose 108 times lower than the oral $\mathrm{LD}_{50}$ (Vidau et al. 2011). Thus, it is clear that exposure of larvae to a range of sublethal doses of neonicotinoid insecticides does not affect their survivorship.

Although there have been several studies on the consumption of pollen by honey bee larvae, there are considerable discrepancies between them. Winston (1991) noted that Alfonsus (1933) described $145 \mathrm{mg}$ and Rosov (1944) described $125 \mathrm{mg}$ of pollen per worker bee larva based on the required amounts for larvae to develop. However, studies on pollen consumption done by counting the number of pollen grains in fully grown worker larvae have estimated 0.4-2.04 mg of pollen per larvae (Simpson 1955; Babendreier et al. 2004). The later studies give much lower values that could be due to the method, which does not account for pre-digestion of pollen before it is fed to larvae by nurse bees, differences between the digestibility of pollen from different plant species (Roulston and Cane 2000) as well as sampling at only one time point (i.e. at the end of larval development). This could underestimate the amount of pollen that larvae consume. This study is based on consumption values related to reports of the amounts needed for larval development rather than pollen grain counts inside larvae. However, if the pollen grain count method were used, then doses in this paper would be much higher than predicted consumption.

Honey bees can be exposed to neonicotinoid insecticides in various ways, such as by exposure to contaminated beeswax or royal jelly (Jabot et al. 2015; Daniele et al. 2018; Böhme et al. 2018). Thus, contamination of beeswax, beebread and royal jelly by neonicotinoid insecticides could have occurred in the colonies we used in this study. However, such effects would have been observed in the control samples as colonies used in this study were collected from the same location with similar chances for contamination. The fate of clothianidin ingested by bees is not clear. However, Brunet et al. (2005) reported that at $72 \mathrm{~h}$ after ingesting a dose of radioactively labelled acetamiprid, a neonicotinoid insecticide, at $1.5 \times$ $10^{3}$ times lower than the $\mathrm{LD}_{50}$, radioactivity was detected in the head of the bees indicating translocation to the brain. Thus, neonicotinoid insecticides can reach the central nervous system of bees, which would bring it into direct contact with nerves, which could result in neurodevelopmental abnormalities during the rapid development of the central nervous system during larval growth, ultimately affecting behaviours of adult honey bees.

Unlike survivorship, clothianidin exposure did affect the proportion of hygienic events in adult bees treated as larvae with the medium and high sublethal doses of clothianidin, although this was not observed with the lowest dose. Hygienic behaviour is associated with a response to olfactory stimuli derived from dead or parasitized larvae and pupae followed by opening of the cell and removal of the affected brood by adult bees (Masterman et al. 2000). As the larvae were treated 25 to 27 days before assessing hygienic behaviour, this indicates surprisingly long-term effects of the pesticide on that behaviour. Bees would typically conduct hygienic events as middle-aged adults between 11 and 17 days post emergence (Invernizzi and Corbella 1999; Arathi et al. 2000), and the assay was done using bees 12, 13 and 14 days post emergence. Thus, it is likely that the effects observed would persist for the entire period when adult bees would normally perform hygienic behaviour.

Similarly, clothianidin at $2 \times 10^{3}$ to $8.1 \times 10^{2}$ times lower than the $\mathrm{LD}_{50}$ negatively affected hygienic behaviour in colonies tested immediately after exposure for 288 days with pollen patties containing clothianidin (Tsvetkov et al. 2017). The related neonicotinoid imidacloprid at $1.18 \times$ $10^{3}$ times lower than the $\mathrm{LD}_{50}$ also decreased hygienic behaviour in colonies tested after exposure for 23 days with a sugar solution containing the pesticide (Wu-Smart and Spivak 2016). In both of those studies, hygienic behaviour was tested at a colony level, and the consumption of insecticide per larvae was not reported, but the colonies were exposed to field realistic conditions; 
the adverse effects on hygienic behaviour reported coincide with the results presented in this study for the medium dose of clothianidin, which is intended to emulate a field realistic exposure to clothianidin.

This is the first report that the hygienic behaviour of bees exposed to sublethal doses of a neonicotinoid insecticide during their larval stage are affected as adults showing the sensitivity and long-term damage of the developing nervous system in larvae to a neonicotinoid. Similarly, long-term neural abnormalities due to neurotoxic pesticides have been shown following pyrethroid exposure during prenatal stages of rats due to dopaminergic alterations in the central nervous system (Dhuriya et al. 2017), and following the organophosphate, metamidiphos, exposure during zebra fish development due to apoptosis in brain cells and a downregulation of neural development-related genes (He et al. 2016). Hence, the effect of sublethal exposures to clothianidin on the central nervous system of developing larvae appears to have long-term negative impacts on at least those neurological functions related to hygienic behaviour. However, the effect of neonicotinoid on other systems that could indirectly affect the performance of hygienic behaviour should be considered. For example, by decreasing the performance of immune responses or muscle function (Christen et al. 2016; Wu et al. 2017). Nonetheless, the impact of sublethal exposures to neonicotinoid insecticides on hygienic behaviour would affect fitness by impairing the colony's ability to defend itself against pathogens by controlling their presence and transmission, which could lead to a decrease in the colony's population or perhaps even death. While exposure of larvae to sublethal doses of clothianidin did not appear to affect foraging based on the duration of the foraging trips performed by adult bees, it did significantly reduce the proportion of bees foraging in general and foraging and returning with pollen for larvae treated with the medium and highest sublethal doses of clothianidin. Thus, exposure of larvae to doses of clothianidin like those found in pollen collected by honey bees could have a detrimental long-term effect on two important components of foraging behaviour. With a lower proportion of bees foraging, there is less potential for food to be gathered for the colony, and with a lower proportion of bees collecting pollen, there would be less protein available for the colony.

Previous studies have reported a reduction in the proportion of forager bees returning to their hives when adults were orally fed with sublethal doses of neonicotinoids (Henry et al. 2012; Fischer et al. 2014; Tosi et al. 2017). In contrast, oral exposure to adults with sublethal doses of neonicotinoid insecticides resulted in no significant effects on mortality, brood development, colony strength and the number of bees foraging or flying around anthers of maize or oilseed rape flowers (Cutler and ScottDupree 2007; Pilling et al. 2013). The difference in the results and conclusions between these studies might be due to the methodologies used, the number of biological replications and the difficulty to control the intrinsic variability within the colonies, as noted by Lundin et al. (2015). However, this study is different from those in that larvae, rather than adults, were exposed to a neonicotinoid insecticide, and thus, this study measures the pesticide's effect on a developing, rather than a mature, central nervous system of the bee, as well as measures its long-term effects. Although previous studies have reported the effect of sublethal exposure at a colony level on foraging behaviour in bumble bees and honey bees (Gill et al. 2012; Dively et al. 2015), this study assessed the effect of sublethal exposure to neonicotinoid insecticides in individual bees exposed during the larval stage and assessed for foraging behaviour as adults.

Although it is difficult to quantify the level of damage on colony fitness due to the impairment of foraging behaviour found in this study, it is possible to estimate the effects of reduced pollen collection on colony populations. Only $15 \%$ and $19 \%$ of the live bees treated as larvae with 0.67 and $1.33 \mathrm{ng}$ of clothianidin, respectively, were foraging for pollen, compared to $25 \%$ of the control. If we consider that a typical colony during the peak of foraging is composed by about 45,000 workers with one third of the workers foraging, performing an average of 12.5 foraging trips a day, with the mean weight of a pollen per trip of $20 \mathrm{mg}$ (Winston 1991), 
then the amount of pollen collected a day for the control would be approximately $903 \mathrm{~g}$ of pollen compared to 589 and $686 \mathrm{~g}$ for the 0.67 and $1.33 \mathrm{ng}$ of clothianidin treatments, respectively. As it requires an average of $145 \mathrm{mg}$ of pollen to produce a honey bee larva (Winston 1991), honey bee colonies exposed to 0.67 and $1.33 \mathrm{ng}$ of clothianidin would rear at least 1518 less larvae every day after exposure compared to unexposed colonies. Over time, this could be highly detrimental as colony growth is an essential component for colony reproduction, productivity and winter survival (Seeley and Visscher 1985). Hence, the impact of sublethal exposure to clothianidin in developing larvae could be translated into a lower number of workers performing tasks necessary for colony productivity, as well as in a lower number of bees necessary for overwinter survival.

In human toxicology, it is well established that neurotoxin exposure of the central nervous system during foetal development causes long-term neurodevelopmental problems resulting in brain dysfunction at doses far below those affecting adult brains (Grandjean and Landrigan 2006). This does not appear to be always similarly appreciated in the study of neurotoxin exposure to honey bees. The long-term effects on adults due to sublethal doses of clothianidin on larvae demonstrates the importance of examining the impacts of neurotoxins on the relatively vulnerable developing nervous system of honey bee larvae, just as it is in studies of neurotoxins on human foetal development.

\section{CONCLUSION}

Honey bees can be unintentionally exposed to sublethal doses of neurotoxins, such as neonicotinoid insecticides, during both adult and larval stages. Studies on the effect of neonicotinoid exposure on different variables, such as foraging behaviour and mortality, have primarily been done on bees exposed as adults (Blacquière et al. 2012). However, the effects on honey bee larvae may be different as neurotoxins are known to have long-term effects on developing brains in animals. We have shown that hygienic and foraging behaviour, but not mortality in adults, are affected by the exposure to sublethal doses of the neonicotinoid insecticide, clothianidin, weeks after exposure during the larval stage. This highlights the long-term negative impacts of this neurotoxin on honey bee development and adult behaviours that are essential for colony survival. Thus, the negative effects of clothianidin exposure to developing bees may persist for most or all of their lifespan.

\section{ACKNOWLEDGEMENTS}

We thank Paul Kelly, Nancy Bradbury, Dave Stotesbury, Santiago Magaña, Brook Wallace, Stephanie Otto, Patrick Boelsteri, Iván Darío Samur, Cassandra Wiesner, Catherin VanderHeyden and Wendy Shipsides for their assistance during the experiments. We also thank Greg J. Hunt and Nigel Raine for their valuable comments of earlier versions of the manuscript.

\section{AUTHORS' CONTRIBUTIONS}

EG project planning and design; NM field experiments and data collection; NM, EG, PHG and AC data analyses. NM, PHG and EG wrote the paper. All authors read and approved the final manuscript.Funding information

This work was partially supported by a New Directions grant from the Ontario Ministry of Agriculture Food and Rural Affairs (OMAFRA) and by a grant from the Pinchin family to EG.

\section{COMPLIANCE AND ETHICAL STANDARDS}

Conflict of interest The authors declare that they have no conflict of interest.

L'exposition sublétale à la clothianidine au stade larvaire entraîne une altération à long terme des comportements d'hygiène et de butinage des abeilles

larve d'abeille mellifère / comportement hygiénique / comportement de butinage / néonicotinoïdes / processus neuronaux

Subletale Exposition mit Clothianidin während der larvalen Entwicklungsphase verursacht Langzeitschädigungen beim Hygiene- und Sammelverhalten von Honigbienen 
Honigbienen-Larven / Hygieneverhalten / Sammelverhalten / Neonikotinoide /

\section{neurale Prozesse}

\section{REFERENCES}

Alfonsus E.C. (1933). Zum Pollenverbrauch des Bienenvolkes. Arch. Bienenkd. 14, 220-223.

Arathi, H. S., Burns, I., Spivak, M. (2000). Ethology of hygienic behaviour in the honey bee Apis mellifera L. (Hymenoptera: Apidae): behavioural repertoire of hygienic bees. Ethology 106(4), 365-379.

Babendreier, D., Kalberer, N., Romeis, J., Fluri, P., Bigler, F. (2004). Pollen consumption in honey bee larvae: a step forward in the risk assessment of transgenic plants. Apidologie, 35(3), 293-300.

Blacquière, T., Smagghe, G., Van Gestel, C.A., Mommaerts, V. (2012). Neonicotinoids in bees: a review on concentrations, side-effects and risk assessment. Ecotoxicology 21(4), 973-992.

Böhme, F., Bischoff, G., Zebitz, C. P., Rosenkranz, P., Wallner, K. (2018). From field to food - will pesticide-contaminated pollen diet lead to a contamination of royal jelly? Apidologie, 49(1), 112-119

Brunet, J.L., Badiou, A., Belzunces, L.P. (2005). In vivo metabolic fate of [14C]-acetamiprid in six biological compartments of the honeybee, Apis mellifera L. Pest Manag. Sci. 61(8), 742-748.

Christen, V., Mittner, F., Fent, K. (2016). Molecular effects of neonicotinoids in honey bees (Apis mellifera). Environ. Sci. Technol. 50(7), 4071-4081.

Costa, L. G., Giordano, G., Guizzetti, M., Vitalone, A. (2008). Neurotoxicity of pesticides: a brief review. Front. Biosci. 13(4), 1240-1249.

Counotte, D.S., Goriounova, N.A., Li, K.W., Loos, M., Van Der Schors, R.C., Schetters, D., Schoffelmeer, A.N., Smit, A.B., Mansvelder, H.D., Pattij, T., Spijker, S. (2011). Lasting synaptic changes underlie attention deficits caused by nicotine exposure during adolescence. Nat. Neurosci. 14(4), 417-419.

Cutler, G. C., Scott-Dupree, C. D. (2007). Exposure to clothianidin seed-treated canola has no long-term impact on honey bees. J. Econ. Entomol. 100(3), 765-772.

Daniele, G., Giroud, B., Jabot, C., Vulliet, E. (2018). Exposure assessment of honeybees through study of hive matrices: analysis of selected pesticide residues in honeybees, beebread, and beeswax from French beehives by LC-MS/ MS. Environ. Sci. Pollut. Res. 25(7), 6145-6153.

Dhuriya, Y. K., Srivastava, P., Shukla, R. K., Gupta, R., Singh, D., Parmar, D., Pant A. B., Khanna, V. K. (2017). Prenatal exposure to lambda-cyhalothrin alters brain dopaminergic signaling in developing rats. Toxicology 386, 49-59.
Dively, G. P., Embrey, M. S., Kamel, A., Hawthorne, D. J., Pettis, J. S. (2015). Assessment of chronic sublethal effects of imidacloprid on honey bee colony health. PloS One, 10(3), e0118748.

Doublet, V., Labarussias, M., de Miranda, J.R., Moritz, R.F., Paxton, R.J. (2015). Bees under stress: sublethal doses of a neonicotinoid pesticide and pathogens interact to elevate honey bee mortality across the life cycle. Environ. Microbiol. 17(4), 969-983.

Esch, H. (2012.) Foraging honey bees: how foragers determine and transmit information about feeding site locations. In: Galizia C., Eisenhardt D., Giurfa M. (Eds), Honeybee neurobiology and behavior. Springer, Berlin, pp. 53-64.

European Food Safety Authority (EFSA). (2013). Conclusion on the peer review of the pesticide risk assessment for bees for the active substance clothianidin. EFSA, 11(1):3066

Fischer, J., Mueller, T., Spatz, A. K., Greggers, U., Gruenewald, B., Menzel, R. (2014). Neonicotinoids interfere with specific components of navigation in honeybees. PloS One 9(3), e91364.

Food and Agriculture Organization (FAO). Specifications and evaluations for agricultural pesticides, thiacloprid. 2010. [ o n $1 \mathrm{ine}$ ] h t t p : / / w w w. f a o . org/fileadmin/templates/agphome/documents/Pests Pesticides/Specs/Thiacloprid 2010.pdf ( accessed 01 January 2019).

Gill, R. J., Ramos-Rodriguez, O., Raine, N. E. (2012). Combined pesticide exposure severely affects individual and colony-level traits in bees. Nature, 491(7422), 105.

Grandjean, P., Landrigan, P.J. (2006). Developmental neurotoxicity of industrial chemicals. Lancet, 368(9553), 2167-2178.

Guzman-Novoa, E., Gary, N. E. (1993). Genotypic variability of components of foraging behavior in honey bees (Hymenoptera: Apidae). J. Econ. Entomol. 86(3), 715-721.

Hamiduzzaman, M.M., Sinia, A., Guzman-Novoa, E., Goodwin, P.H. (2012). Entomopathogenic fungi as potential biocontrol agents of the ecto-parasitic mite, Varroa destructor, and their effect on the immune response of honey bees (Apis mellifera L.). J. Invertebr. Pathol. 111(3), 237-243.

He, X., Gao, J., Dong, T., Chen, M., Zhou, K., Chang, C., Luo J., Wang C., Chen D., Zhou, Z., Tian Y., Xia Y., Wang X. (2016). Developmental neurotoxicity of methamidophos in the embryo larval stages of zebrafish. Int. J. Environ. Res. Public Health 14(1), 23-34.

Henry, M., Beguin, M., Requier, F., Rollin, O., Odoux, J. F., Aupinel, P., Aptel J., Tchmitchian S., Decourtye, A. (2012). A common pesticide decreases foraging success and survival in honey bees. Science 336(6079), 348-350.

Invernizzi C., Corbella E. (1999). Edad de las obreras que realizan comportamiento higiénico y otros comportamientos en las abejas Apis mellifera, Revista de Etología 2, 78-87.

Jabot, C., Fieu, M., Giroud, B., Buleté, A., Casabianca, H., Vulliet, E. (2015). Trace-level determination of 
pyrethroid, neonicotinoid and carboxamide pesticides in beeswax using dispersive solid-phase extraction followed by ultra-high-performance liquid chromatography-tandem mass spectrometry. Int. J. Environ. Anal. Chem. 95(3), 240-257.

Lundin, O., Rundlöf, M., Smith, H. G., Fries, I., Bommarco, R. (2015). Neonicotinoid insecticides and their impacts on bees: a systematic review of research approaches and identification of knowledge gaps. PLoS One 10(8), e0136928.

Masterman, R., Smith, B. H., Spivak, M. (2000). Brood odor discrimination abilities in hygienic honey bees (Apis mellifera L.) using proboscis extension reflex conditioning. J. Insect Behav. 13(1), 87-101.

Page Jr, R. E. (2012). The spirit of the hive and how a superorganism evolves. In: Galizia C., Eisenhardt D., Giurfa M (Eds.), Honeybee neurobiology and behavior. Springer, Berlin, pp. 3-16.

Pilling, E., Campbell, P., Coulson, M., Ruddle, N., Tornier, I. (2013). A four-year field program investigating longterm effects of repeated exposure of honey bee colonies to flowering crops treated with thiamethoxam. PLoS One 8(10), e77193.

Pisa, L. W., Amaral-Rogers, V., Belzunces, L. P., Bonmatin, J. M., Downs, C. A., Goulson, D., Kreutzweiser D.P., Krupke C., Liess M., McField M., Morrisey C.A., Noome D.A., Settele J., Simmon-Delso N., Stark D. (2015). Effects of neonicotinoids and fipronil on nontarget invertebrates. Environ. Sci. Pollut. R. 22(1), 68102.

R Core Team (2014). R: A language and environment for statistical computing. R Foundation for Statistical Computing, Vienna, Austria. URL http://www.R-project.org/.

Rosov, S.A. (1944). Food consumption by bees. Bee World 25, 94-95.

Roulston, T.H., Cane, J. H. (2000). Pollen nutritional content and digestibility for animals. Plant Syst. Evol. 222: 187-209.

Seeley, T. D., Visscher, P. K. (1985). Survival of honeybees in cold climates: the critical timing of colony growth and reproduction. Ecol. Entomol. 10(1), 81-88.

Simpson, J. (1955). The significance of the presence of pollen in the food of worker larvae of the honey-bee. J. Cell Sci. 3(33), 117-120.

Slotkin, T.A., 2004. Cholinergic systems in brain development and disruption by neurotoxicants: nicotine, environmental tobacco smoke, organophosphates. Toxicol. Appl. Pharmacol. 198(2), 132-151.

Spivak, M. (1996). Honey bee hygienic behavior and defense against Varroa jacobsoni. Apidologie 27(4), 245-260.

Spivak, M., Reuter, G. S. (2001). Resistance to American foulbrood disease by honey bee colonies Apis mellifera bred for hygienic behavior. Apidologie 32(6), 555-565.

Spivak, M., Masterman, R., Ross, R., Mesce, K. A. (2003). Hygienic behavior in the honey bee (Apis mellifera L.) and the modulatory role of octopamine. Dev. Neurobiol. 55(3), 341-354.

Tan, K., Chen, W., Dong, S., Liu, X., Wang, Y., Nieh, J.C. (2015). A neonicotinoid impairs olfactory learning in Asian honey bees (Apis cerana) exposed as larvae or as adults. Sci. Rep. 5, 10989.

Tomizawa, M., Casida, J.E. (2008). Molecular recognition of neonicotinoid insecticides: the determinants of life or death. Acc. Chem. Res. 42(2), 260-269.

Tosi, S., Burgio, G., Nieh, J. C. (2017). A common neonicotinoid pesticide, thiamethoxam, impairs honey bee flight ability. Sci. Rep. 7(1), 1201.

Tsvetkov, N., Samson-Robert, O., Sood, K., Patel, H. S., Malena, D. A., Gajiwala, P. H., Maciukiewicz P., Fournier V., Zayed, A. (2017). Chronic exposure to neonicotinoids reduces honey bee health near corn crops. Science 356(6345), 1395-1397.

Uneme, H. (2010). Chemistry of clothianidin and related compounds. J. Agric.Food Chem. 59(7), 2932-2937.

Unger, P., Guzman-Novoa, E. (2010). Maternal effects on the hygienic behavior of Russian $\times$ Ontario hybrid honeybees (Apis mellifera L.). J. Hered. 101(1), 91-96.

Vidau, C., Diogon, M., Aufauvre, J., Fontbonne, R., Viguès, B., Brunet, J.L., Texier, C., Biron, D.G., Blot, N., El Alaoui, H., Belzunces, L.P. (2011). Exposure to sublethal doses of fipronil and thiacloprid highly increases mortality of honeybees previously infected by Nosema ceranae. PLoS One 6(6), p.e21550.

Webb, B. (2012). Cognition in insects. Philos. Trans. Royal. Soc. B. 367(1603), 2715-2722.

Winston, M. L. (1991). The biology of the honey bee. $\left(1^{\text {st }}\right.$ ed). Harvard University Press, Cambridge.

Wu, Y.Y., Luo, Q.H., Hou, C.S., Wang, Q., Dai, P.L., Gao, J., Liu, Y.J., Diao, Q.Y. (2017). Sublethal effects of imidacloprid on targeting muscle and ribosomal protein related genes in the honey bee Apis mellifera L. Sci. Rep., 7 (1), 15943.

Wu-Smart, J., Spivak, M. (2016). Sub-lethal effects of dietary neonicotinoid insecticide exposure on honey bee queen fecundity and colony development. Sci. Rep., 6(32108), 1-11.

Yang, E.C., Chang, H.C., Wu, W.Y., Chen, Y.W. (2012). Impaired olfactory associative behavior of honeybee workers due to contamination of imidacloprid in the larval stage. PloS One 7(11), p.e49472.

Zahalka, E.A., Seidler, F.J., Lappi, S.E., McCook, E.C., Yanai, J., Slotkin, T.A. (1992). Deficits in development of central cholinergic pathways caused by fetal nicotine exposure: differential effects on choline acetyltransferase activity and $[3 \mathrm{H}]$ hemicholinium-3 binding. Neurotoxicol. Teratol. 14(6), 375-382.

Publisher's note Springer Nature remains neutral with regard to jurisdictional claims in published maps and institutional affiliations. 